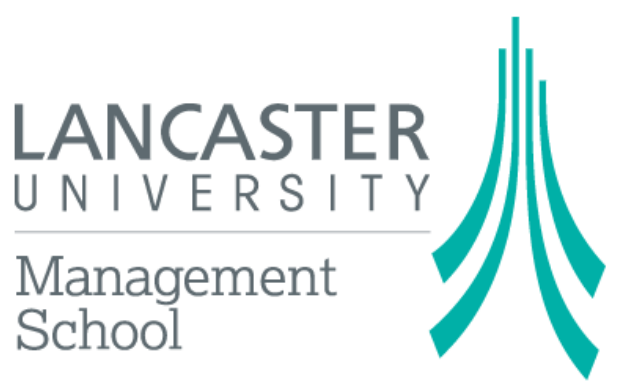

Economics Working Paper Series

2014/028

\title{
Turnout and Polarization under Alternative Electoral Systems
}

Konstantinos Matakos, Orestis Troumpounis and Dimitrios Xefteris

The Department of Economics

Lancaster University Management School

Lancaster LA1 4YX

UK

(C) Authors

All rights reserved. Short sections of text, not to exceed two paragraphs, may be quoted without explicit permission, provided that full acknowledgement is given. 


\title{
Turnout and Polarization under Alternative Electoral Systems
}

\author{
Konstantinos Matakos* ${ }^{*}$ Orestis Troumpounis ${ }^{\dagger} \quad$ Dimitrios Xefteris $^{\ddagger}$
}

August 26, 2014

\begin{abstract}
We present a formal model of electoral competition where parties' platforms are endogenously chosen and depend on the degree of the electoral rule disproportionality. We first show that proportional electoral systems generate centrifugal forces that increase candidate differentiation. This in turn implies that more proportional systems are associated with lower levels of abstention from indifference. This two step theoretical prediction of the effect of electoral systems on turnout is then empirically validated even when we jointly control for the prevailing pivotality and party-system size hypotheses. Thus, our work highlights an additional link in the proportionality-turnout nexus.
\end{abstract}

*London School of Economics and Political Science, Government Department, Connaught Hall CON.5.10, London WC2A 2AE, UK; e-mail: k.matakos@lse.ac.uk

${ }^{\dagger}$ Department of Economics, Lancaster University, The Management School, Bailrigg, LA1 4YX, UK, e-mail: o.troumpounis@lancaster.ac.uk

${ }^{\ddagger}$ Department of Economics, University of Cyprus, PO Box 20537, 1678 Nicosia, Cyprus, e-mail: xefteris.dimitrios@ucy.ac.cy 


\section{Introduction}

The effect of electoral rules on voter turnout has been extensively studied. ${ }^{1}$ Most empirical studies tend to report a regularity that can be summarized as follows: more proportional electoral rules are associated with higher political participation and voter turnout (see Jackman 1987; Jackman and Miller 1995; Powell Jr 1980, 1986; Blais and Dobrzynska 1998; Blais and Carty 1990 among others). Yet, even if this relationship holds there is less understanding and agreement on the forces and the exact mechanisms that give rise to this regularity (for a discussion see Herrera et al. 2013; Selb 2009).

According to the "calculus of voting" model, voter turnout depends on two forces: the probability that a voter can affect the outcome (pivotality) and the benefit associated with altering the outcome of the election. In order for a voter to participate in the election the expected benefit (Pivotality*Benefit) has to compensate the cost of voting. ${ }^{2}$ That is:

\section{Pivotality $*$ Benefit $>$ Cost of Voting}

If this model describes reasonably well the behavior of real voters, electoral rules should be indeed relevant for determining voter turnout since they clearly affect both parameters of the left hand side of the inequality.

Electoral rules can affect the relative competitiveness of the electoral race at the district level and hence, they can affect the probability that a voter is pivotal. For instance, proportional rules with multi-member districts tend to generate more competitive districts as every vote counts. On the other hand, first-past-the-post electoral rules with single-member districts (SMD) tend to have higher variability in the degree of district competitiveness: in the same election some districts might be very competitive while

\footnotetext{
${ }^{1}$ The literature is huge and we do not aim to review it. For related surveys refer for example to Geys (2006); Blais (2006).

${ }^{2}$ Despite the critique on the rational choice model of voter turnout, it is widely accepted (see Selb 2009 and others) that the calculus of voting model can be very useful in explaining variations in voter turnout. While the original formulation by Riker and Ordeshook (1968) also contains the benefit of the act of voting on the left hand side voting here our cost can be understood as the net cost of voting after having subtracted the latter.
} 
others might not be competitive at all. Hence, the degree of district competitiveness is indeed a channel through which electoral rules might affect voter turnout and for this reason most previous studies have focused on providing evidence in favour of this hypothesis (Selb 2009). Their claim is that the observed empirical pattern can be explained via the following mechanism: proportional rules increase average district competitiveness and hence voter turnout. This is particularly problematic for two reasons. Firstly, as Grofman and Selb (2011) show district magnitude and the proportionality of the electoral rule may not be good predictors of the pivotality of a given race. Second, and most importantly, recent experimental evidence by Enos and Fowler (2014) who test the hypothesis that "greater electoral competition and the increased chance of pivotality will motivate citizens to participate" have found that "the predominant models of turnout focusing on pivotality are of little practical use".

The second channel (i.e. benefit) through which electoral rules might affect voter turnout has received less attention and it was explored mainly through the effect that electoral rules have on the number of competing parties and the size of the party-system. Contrary to what one would expect many empirical studies have found that larger partysystems are in fact depressing voter turnout (e.g., Blais and Dobrzynska 1998; Blais and Carty 1990; Jackman 1987; Jackman and Miller 1995). That is, there is no solid empirical support for this second channel through which electoral rules should affect voter turnout and, hence, no solid empirical support for the "calculus of voting" model as a whole.

This study aims to provide support in favour of this second channel by uncovering a missing link in the relationship between electoral rule disproportionality and voter turnout: the effect of electoral systems on platform polarization and hence abstention associated with the latter. We first present a formal model where parties' platform are chosen endogenously and depend on the degree of the electoral rule disproportionality. In line with our previous research (Matakos et al., 2013) we show that more proportional rules generate centrifugal forces that increase platform divergence and candidate differ- 
entiation. ${ }^{3}$ This, in turn, increases the stakes of the election for the voter: as parties' platforms diverge, for any given cost of voting and race closeness, more voters are willing to vote as they are less likely to be indifferent among the proposed alternatives.

This main prediction of our theoretical model is then empirically tested. As it is obvious, this is a two-step hypothesis stating that the disproportionality of the electoral rule indirectly affects voter turnout by altering the positions (platforms) that parties take in the policy dimension. That is, there appears to be a missing link in the nexus between electoral rule disproportionality and voter turnout. As our empirical results show this hypothesis is empirically validated even when we control jointly for the prevailing pivotality and party-system size hypotheses.

The chapter is structured as follows: We first present our theoretical model and its main predictions. We then state our main hypothesis, describe the data and present our empirical results. Finally we provide some concluding remarks.

\section{Theory}

We consider two parties $(j=L, R)$ that compete in an election by simultaneously announcing platforms $\left(p_{L}\right.$ and $\left.p_{R}\right)$. After both parties announce their platforms the voting stage follows which determines parties' vote-shares $\left(V_{L}\right.$ and $\left.V_{R}\right)$. Given parties' voteshares $\left(V_{L}\right.$ and $\left.V_{R}\right)$, the announced platforms $\left(p_{L}\right.$ and $\left.p_{R}\right)$, and the (dis)proportionality of the electoral system $(n)$ a policy $\hat{p}$ is implemented.

The policy space is assumed to be continuous, one-dimensional and is represented by the interval $\Pi=[0,1]$. We assume that each voter has symmetric and single-peaked preferences on the policy space. In particular we consider that if $\pi_{i} \in \Pi$ denotes the ideal policy of voter $i$, then the utility that voter $i$ derives from policy $p \in \Pi$ is given by

\footnotetext{
${ }^{3}$ Several justifications for platform divergence are well established. These may vary from informational or media-related factors (e.g., Grosser and Palfrey 2013; DellaVigna and Kaplan 2007) to candidates' diverging policy preferences (e.g., Calvert 1985; Roemer 1994) and candidates' valence characteristics (e.g., Groseclose 2001; Aragonès and Palfrey 2002; Aragonès and Xefteris 2012; Schofield and Sened 2006; Schofield and Gallego 2011; Schofield and Kurella 2013; Serra 2010).
} 


$$
u_{i}(p)=-\left(\pi_{i}-p\right)^{2}
$$

Each voter, observes the platforms proposed by the two parties and decides whether to vote for one of the two parties or to abstain. The rule that determines voters' behavior is the following: voter $i$ votes for party $L$ if $u_{i}\left(p_{L}\right)-u_{i}\left(p_{R}\right)>v$, votes for party $R$ if $u_{i}\left(p_{R}\right)-u_{i}\left(p_{L}\right)>v$ and abstains otherwise. The value of $v$ is assumed to be non-negative and common for all voters. Parameter $v$ is the so called indifference threshold above which a voter is willing to vote for the party that is closest to his ideal point (Riker et al., 1973; Enelow and Hinich, 1984; Adams et al., 2005). The higher this threshold is the larger the difference between the two proposed platforms must be so that it is worthwhile for a voter to participate in the election. If $v$ is low then voters are willing to participate even if parties' platforms do not differentiate significantly.

The above imply that if, for example, $p_{L}<p_{R}$ all voters with ideal policies smaller than $\max \left\{0, \frac{v+p_{L}^{2}-p_{R}^{2}}{2 p_{L}-2 p_{R}}\right\}$ vote for party $L$, all voters with ideal policies from $\max \left\{0, \frac{v+p_{L}^{2}-p_{R}^{2}}{2 p_{L}-2 p_{R}}\right\}$ to $\min \left\{\frac{-v+p_{L}^{2}-p_{R}^{2}}{2 p_{L}-2 p_{R}}, 1\right\}$ abstain and all voters with ideal policies larger than $\min \left\{\frac{-v+p_{L}^{2}-p_{R}^{2}}{2 p_{L}-2 p_{R}}, 1\right\}$ vote for party $R$. Notice that abstainers are more or less moderate individuals which are relatively indifferent between the two platforms.

We assume that there exists a unit mass of voters and that their ideal policies are uniformly distributed on $\Pi=[0,1]$. Therefore parties' vote-shares are given by

$$
V_{L}\left(p_{L}, p_{R}\right)= \begin{cases}\max \left\{0, \frac{v+p_{L}^{2}-p_{R}^{2}}{2 p_{L}-2 p_{R}}\right\}, & \text { if } p_{L}<p_{R} \\ 0, & \text { if } p_{L}=p_{R} \\ 1-\min \left\{\frac{v+p_{L}^{2}-p_{R}^{2}}{2 p_{L}-2 p_{R}}, 1\right\}, & \text { if } p_{L}>p_{R}\end{cases}
$$

and

$$
V_{R}\left(p_{L}, p_{R}\right)=\left\{\begin{array}{ll}
1-\min \left\{\frac{-v+p_{L}^{2}-p_{R}^{2}}{2 p_{L}-2 p_{R}}, 1\right\}, & \text { if } p_{L}<p_{R} \\
0, & \text { if } p_{L}=p_{R} \\
\max \left\{0, \frac{-v+p_{L}^{2}-p_{R}^{2}}{2 p_{L}-2 p_{R}}\right\}, & \text { if } p_{L}>p_{R}
\end{array} .\right.
$$

In order to illustrate voters' behavior consider the following examples depicted in figure 1. In the two first examples the proposed platforms are quite differentiated $\left(\left(p_{L}, p_{R}\right)=\right.$ 

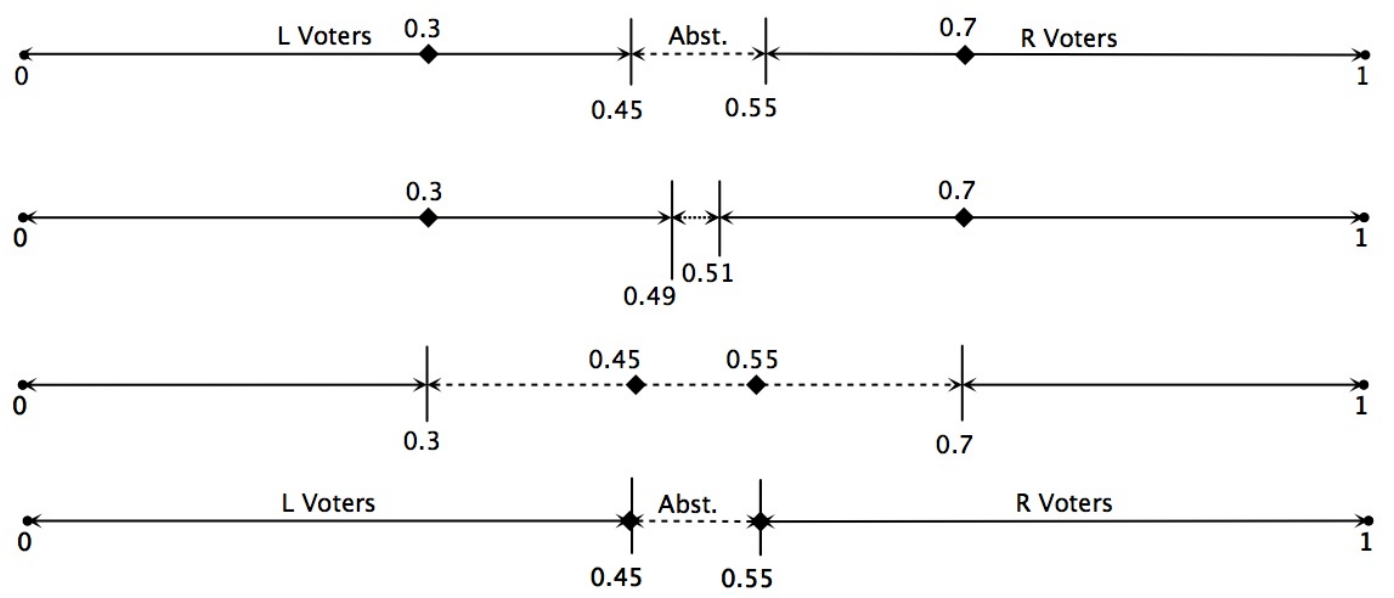

Figure 1: Solid lines represent voters and dashed lines abstainers. Diamonds represent parties' proposed platforms. In the first and third example $v=0.04$ and in the second and fourth example $v=0.01$.

$(0.3,0.7))$ while in the two last examples parties propose less differentiated platforms $\left(\left(p_{L}, p_{R}\right)=(0.45,0.55)\right)$. In the first and third example we consider that voters have a high cost of supporting platforms that are not differentiated enough $(v=0.04)$ while this cost is much lower in the second and fourth example $(v=0.01)$. As one can see turnout can vary from sixty (third example where platforms are similar and $v$ is high) to ninety-seven and a half percent (second example where platforms are differentiated and $v$ is low). Lowest turnout levels are observed when platforms are very similar and costs are high while the highest turnout is observed when costs are low and parties are differentiated. Notice that in all four examples it is the relatively moderate voters that abstain. Nevertheless, these do not necessarily have to lie between the proposed platforms (see example three). Finally, notice that for a given cost turnout is higher the more differentiated the platforms are.

Parties are policy motivated. Their payoffs depend on the implemented policy rather than on an exogenous given office value for winning the election. Each party $j$ has an ideal policy $\pi_{j} \in \Pi$. We assume that parties have an ideal policy at the extremes of the policy line, that is, $\pi_{L}=0$ and $\pi_{R}=1$ and that party's $j$ preferences over policies are the same as the preferences of a voter with the same ideal policy. Therefore parties want the implemented policy to be as close as possible to one of the two extremes of the policy 


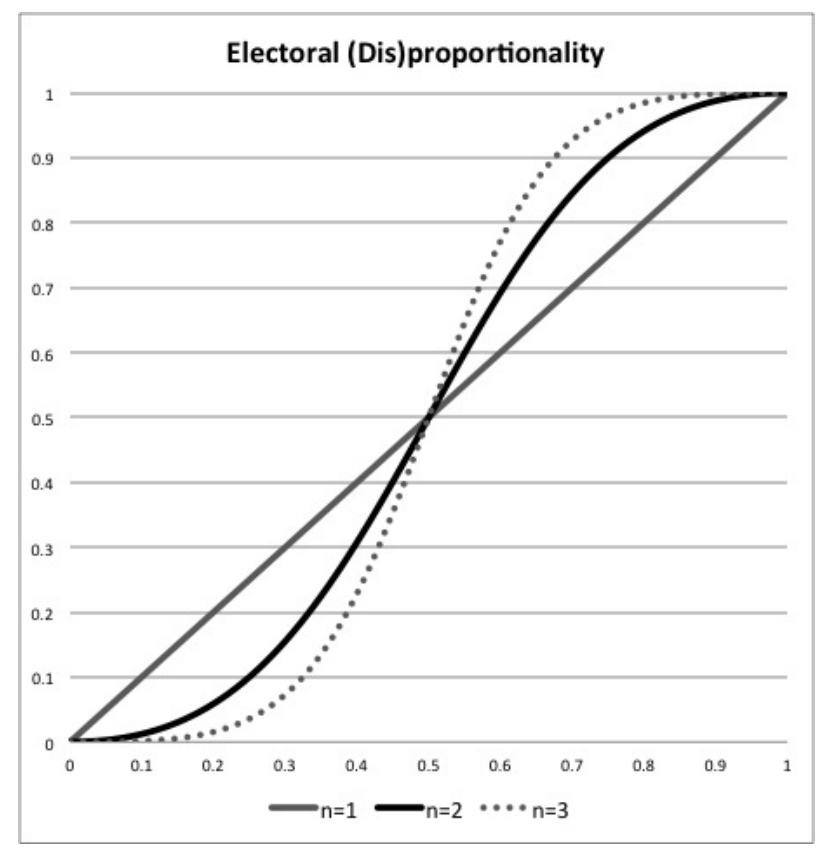

Figure 2: The weight of a party's proposal (i.e. its seat-share) as a function of its voteshare for the cases where $n=1, n=2$, and $n=3$.

space. Let us mention that our results are robust to parties with non-extreme policy preferences.

The implemented policy is determined through the parliamentary mean model (OrtuñoOrtín, 1997; Llavador, 2006; De Sinopoli and Iannantuoni, 2007; Matakos et al., 2013; Saporiti, 2014). This means that the implemented policy is a weighted average of parties' parliamentary power. Notice that parties' seat-shares are of course a function of parties' vote-shares $\left(V_{L}, V_{R}\right)$ which ultimately are a function of the proposed platforms and the disproportionality of the electoral system denoted by $n$, where $n \geqslant 1$. Following our previous work the way parties' vote-shares $\left(V_{L}\right.$ and $\left.V_{R}\right)$ translate into seat-shares $\left(S_{L}\right.$ and $\left.S_{R}\right)$ in the parliament depends on the disproportionality of the electoral system $(n)$ and follows Theil (1969):

$$
\frac{S_{L}}{S_{R}}=\left(\frac{V_{L}}{V_{R}}\right)^{n}
$$

Through the above formula and $n=1$ one captures a purely proportional representation system where no distortions are present. Letting $n=3$ the seat allocation is based 
on the famous "cube law" which is used in the literature as a good approximation of the distortions created in favour of the winner in first past the post single (FPTP) elections. In general as $n$ increases the electoral system is more disproportional in favour of the winner of the election. The implemented policy function can then be rewritten as:

$$
\hat{p}\left(p_{L}, p_{R}, n\right)=\frac{V_{L}\left(p_{L}, p_{R}\right)^{n}}{V_{L}\left(p_{L}, p_{R}\right)^{n}+V_{R}\left(p_{L}, p_{R}\right)^{n}} * p_{L}+\frac{V_{R}\left(p_{L}, p_{R}\right)^{n}}{V_{L}\left(p_{L}, p_{R}\right)^{n}+V_{R}\left(p_{L}, p_{R}\right)^{n}} * p_{R}
$$

where the proposed platforms $p_{L}$ and $p_{R}$ are weighted by parties' parliamentary power $S_{L}$ and $S_{R}$. In figure 2 we depict how vote-shares translate to parliamentary power and the effect of $n$ on the latter. If for example we are under a FPTP rule $(n=3)$ then a sixty percent vote-share would translate to seventy seven percent of the parliamentary power compared to a sixty percent power in case of a pure proportional representation system $(n=1)$. When turnout is zero we assume that

$$
\hat{p}\left(p_{L}, p_{R}, n\right)=\frac{p_{L}+p_{R}}{2}
$$

Individuals decide non strategically whether to vote for one of the parties or not once they observe the announced platforms. Hence, parties are the only players of the game and strategically announce their platforms. The equilibrium concept we apply is Nash equilibrium in pure strategies.

\section{$2.1 \quad$ Results}

To avoid technical complexities that have to do with discontinuities of the payoff function for large parameter values we restrict attention to $n \in\{1,2,3\}$ and $v \in[0,0.05]$. We regard these ranges of parameter values, though, as the most relevant ones: $n=1$ represents a pure proportional representation rule while $n=3$ is understood in the literature to better represent elections with single-member districts, the most disproportional kind of elections at least among parliamentary ones (Taagepera, 1986). It follows than $n=2$ represents mixed systems. Finally $v=0$ ensures a $100 \%$ turnout for any $p_{L} \neq p_{R}$ while 
$v=0.05$ can generate arbitrarily low turnout when platforms are sufficiently similar. Our theoretical predictions follow.

Proposition 1. (i) There exists a unique electoral equilibrium

$$
\left(p_{L}^{*}, p_{R}^{*}\right)=\left(\frac{-1+2 n-\sqrt{1-4 v n}}{4 n}, \frac{1+2 n+\sqrt{1-4 v n}}{4 n}\right)
$$

(ii) The distance between $p_{R}^{*}$ and $p_{L}^{*}$ is decreasing in $n$.

\section{All proofs can be found in the appendix}

Our first theoretical result provides the unique equilibrium of the electoral game presented in the previous section. The second part of our proposition relates electoral rule disproportionality with platform polarization and, in line with Matakos et al. (2013), it shows that parties platforms are less polarized under more disproportional electoral systems. In general, a move towards the center has two opposing effects on the welfare of a party (say for example the leftist one): ceteris paribus, it pushes the implemented policy away from the party's ideal policy $\left(S_{L} * p_{L}+S_{R} * p_{R}\right.$ is increasing in $p_{L}$ when $S_{L}$, $S_{R}$ and $p_{R}$ are constant) but also it drags the implemented policy close to the party's ideal policy as a move towards the median increases the party's vote-share and hence its weight in the implemented policy $\left(S_{L} * p_{L}+S_{R} * p_{R}\right.$ is decreasing in $S_{L}$ when $p_{L}, S_{R}$ and $p_{R}$ are constant). As the disproportionality of the electoral system increases, proposing a moderate platform may be worthwhile since the incentives to obtain some extra votes are amplified.

Given that the equilibrium turnout is given by the sum of the equilibrium vote-shares of party $L$ and $R$ one can obtain the equilibrium turnout under a rule $n$ using the following expression:

$$
\begin{gathered}
T^{*}(n)=V_{L}\left(\frac{-1+2 n-\sqrt{1-4 v n}}{4 n}, \frac{1+2 n+\sqrt{1-4 v n}}{4 n}\right)+V_{R}\left(\frac{-1+2 n-\sqrt{1-4 v n}}{4 n}, \frac{1+2 n+\sqrt{1-4 v n}}{4 n}\right)= \\
=\frac{1}{2}+\frac{1}{2} \sqrt{1-4 v n} .
\end{gathered}
$$


Proposition 2. For every $v \in(0,0.05]$ equilibrium turnout, $T^{*}(n)$, is strictly decreasing in $n \in[1,3]$.

Proposition 2 makes a clear prediction regarding the relationship between the electoral rule disproportionality and voter turnout that can be tested against the data. It shows that the disproportionality of the electoral rule (measured by the majoritarian bias parameter $n$ ) has a negative effect on voter turnout. As we have demonstrated this effect operates via the endogenous choice of parties' platforms and the larger fraction of voters who abstain from indifference; as the disproportionality of the electoral system increases, parties choose less differentiated platforms and more people become relatively indifferent between them. In line with the predictions of our formal model we formulate the following hypothesis:

(H.1) Platform Distance Hypothesis: Voter turnout is increasing in the distance between parties' platforms (measured by polarization) which, in turn, is decreasing in the disproportionality of the electoral rule (measured by $n$ ).

In addition to our main theoretical prediction above, we also test two other hypotheses that were put forward by past literature. The reason is that in our effort to uncover a missing link in the proportionality-turnout nexus it is important to document that this effect is present even if one accounts for the other two theoretical mechanisms that were previously discussed. That is, we will document that our proposed mechanism, which was largely ignored by past literature, operates in addition to the competitiveness and party system hypotheses. Formally, we test the following two complementary hypotheses:

(H.2) Competitiveness-Pivotality Hypothesis: Weak electoral competition and the resulting decreased chance of pivotality are suppressing voter turnout.

(H.3) Party-System Size Hypothesis: Voter turnout is increasing in the number of competing parties.

The last two hypotheses have been explored by a number of related studies in the past yielding inconclusive evidence. While most studies refute H.3 (e.g. Blais and Aarts 


\begin{tabular}{lccccc}
\hline \hline Variable & Obs. & Mean & Std. Dev. & Min & Max \\
\hline Electoral Margin of Victory & 302 & 9.87 & 7.93 & 0.1 & 34.4 \\
Voter Turnout (in \%) & 307 & 79.73 & 12.36 & 35.8 & 95.8 \\
Electoral Rule Dummy (FPTP =1) & 307 & 0.17 & 0.38 & 0 & 1 \\
Majoritarian Bias Parameter (n) & 255 & 1.70 & 0.89 & 1 & 3.42 \\
Type of Political Regime (Presidential = 1) & 251 & 0.25 & 0.43 & 0 & 1 \\
Coalition Habbits Dummy (Coal. Govt.= 1) & 290 & 0.57 & 0.50 & 0 & 1 \\
Polarization (Dalton Index 0-10) & 307 & 1.70 & 0.79 & 0.23 & 5.14 \\
Polarization (MDP Index 0-10) & 307 & 2.43 & 1.10 & 0.34 & 6.55 \\
Electoral District Magnitude (Average) & 255 & 17.70 & 35.04 & 1 & 150 \\
Log Avg. Electoral District Magnitude & 255 & 1.78 & 1.43 & 0 & 5.01 \\
Years of consolidated Democracy & 254 & 49.87 & 20.73 & 1 & 87 \\
Effective Number of Electoral Parties & 307 & 4.06 & 1.49 & 2.0 & 10.3 \\
Actual Number of Parties & 307 & 5.65 & 2.18 & 1 & 12 \\
\# Parties participating in Gov't/Cabinet & 250 & 2.03 & 1.27 & 1 & 6 \\
Degree of Institutional Constraints (0-6) & 305 & 2.15 & 1.47 & 0 & 5 \\
\hline \hline Note: Data reported at electoral not calendar year. Source: Comparative Political Studies Data Set 1, Carey-Hix Data \\
Archive and the Manifesto Project Database. Period of observation: $1960-2007$ for 23 OECD States. &
\end{tabular}

2006; Powell 2000) finding the effect of party-system size on turnout to be negative, the evidence for H.2 is mixed; some studies (e.g. Selb 2009) provide conditional support for the Competitiveness-Pivotality hypothesis and others (e.g. (Enos and Fowler, 2014)) call those earlier findings into question. By testing all three hypotheses together, we aim at uncovering a third link between electoral rules and voter turnout.

\section{Data and methodology}

Our data set contains electoral, political, institutional, socioeconomic, and demographic observations for more than 300 elections from 23 OECD countries during the period from 1960 to 2006 by combining three different sources (Carey, 2012; Armingeon et al., 2012; Volkens et al., 2012). As a result, our data are suitable for a cross-country pooled timeseries analysis (see also Matakos et al. 2013). Summary statistics for our main variables can be found in Table 1 . 


\section{The Dependent Variable: Voter Turnout}

Our dependent variable is retrieved from the Armingeon et al. (2012) Comparative Political Data Set I (CPDS-I) compiled by the University of Bern. We have chosen to focus on voter turnout as it is the most direct and easily measurable index of civic engagement and participation with the political affairs of the state. Moreover, the variable exhibits sufficient variation both over time and also across countries. ${ }^{4}$

The Main Explanatory Variables: Polarization, Electoral Margins and the Number of Competing Parties

Our key explanatory variable, platform polarization, is constructed using data from the Volkens et al. (2012) Comparative Manifesto Project (CMP) Data Set compiled by the Berlin Centre for Social Research (WZB). The latter records the ideological position of the platforms proposed by hundreds of political parties since 1946. In line with our theoretical model we consider a unidimensional policy space in a $0-10$ scale where zero stands for extreme left and ten for extreme right. ${ }^{5}$ In order to maintain consistency with our theoretical model as well as with previous literature we measure polarization in two different ways. First, as the Most Distant Platforms (MDP) index which captures the distance between the two most distant platforms (e.g., Budge and McDonald 2006; Andrews and Money 2009). This allows for a one-to-one correspondence between our theoretical predictions and the empirical estimation but it has the following drawback: sometimes the two most distant platforms belong to parties that are frictional and receive tiny vote-shares. As a result, they do not seem to matter a lot in terms of electoral competition and policy formation which implies that the platforms of those parties may not be relevant from the voters' perspective.

In order to address this complication, following Dalton (2008), we also use a second index of platform polarization. ${ }^{6}$ Formally, we define the Dalton index of platform

\footnotetext{
${ }^{4}$ There are some countries in our sample (Australia, Belgium and Switzerland) that have introduced compulsory voting laws. We deal with those complications in the next section, when we present our econometric modelling strategy.

${ }^{5}$ Technically, the CMP provides parties' positions on a -100 to 100 scale. We perform an affine, monotonic, order preserving transformation of the index.

${ }^{6}$ Curini and Hino (2012) also use the Dalton index while Ezrow (2008) and Dow (2011) use a very
} 
polarization $\left(I P_{i}\right)$ in election $i$ as:

$$
I P_{i}=\sqrt{\sum_{j} V_{j}\left(\frac{p_{j}-\bar{p}}{0.5}\right)^{2}}
$$

where $\bar{p}$ denotes the weighted mean of parties' proposed platforms (each party $j$ is weighted by its vote-share $\left.V_{j}\right), p_{j}$ is the platform proposed by party $j$ while the difference between the two is normalized by the mid-point ideology position (in our case 0.5 ). It is easily checked that the Dalton index takes value 0 when all parties converge to a single position and 10 when parties are equally split between the two extreme positions. Weighting for the electoral size of each party implies that a large party at one of the extremes induces greater polarization than a frictional party occupying the same position. This property of the Dalton index is of particular importance as it assigns higher weight to platform differentiations that are more relevant from the voters' perspective. Clearly, a voter is more concerned when two big parties, that have good chances of winning elections (and also affecting policy formation), are diverging than the case of two marginal parties (with no chance of participating in government or influencing policy) positioning themselves to the two extremes. In general, as we will later show, our findings are robust to the use of either of the two indices of polarization. We therefore present our estimates (in Tables 2 and 3) using both measures of polarization and show that our main results are consistent with the theoretical prediction and the hypotheses outlined above.

Our second variable of interest is the margin of electoral victory measured by the percentage margin between the winner and the runner-up candidate or party. This approach of capturing the closeness of the electoral race, has been used extensively in the literature (e.g. Selb 2009) despite some critique (e.g. Cox 1988; Elkins 1974) as a rough approximation of the competitiveness of the race, which in turn, determines the degree of pivotality. ${ }^{7}$ Clearly, in the case of SMD or two-party elections the electoral margin

\footnotetext{
close analogue.

${ }^{7}$ The most common critique is centred on the fact that actual election results may not accurately reflect pre-election expectations. However, as Selb (2009) notes "because ex ante information such as forecasts based on pre-election polls are usually not available for all the districts of a given electoral
} 
between the winner and the runner-up of the election is a very good approximation of how competitive the race is. Nevertheless, this is not straightforward in the case of multimember districts with more than two competing parties. To tackle this issue, previous literature has suggested two possible ways ahead, which we nonetheless find equally problematic. The first one is to consider the contest and the margin for the final seat. The second is to calculate the effective threshold of exclusion that indicates the maximum vote-share with which it is possible not to win a seat and as a result it is argued that it provides the lower bound on the competitiveness of a given district. ${ }^{8}$

Yet, there are a number of complications related to the use of any of those two proposed measures of the competitiveness of the electoral race for multi-member proportional representation $(\mathrm{PR})$ districts. The first one is that both critically depend on the magnitude (size) of the electoral district. That is, instead of capturing the closeness of a given electoral race in a specific district they simply capture the institutionally induced competitiveness of an average race. Moreover, as Grofman and Selb (2009) demonstrate not all PR systems are generating identical turnout incentives. In addition, in a follow-up paper (Grofman and Selb, 2011) they show that not only proportionality does not necessarily have to increase with district magnitude, but at the same time the competitiveness of an electoral race does not necessarily increase with district magnitude. To see this, observe that the threshold of exclusions is uniquely determined by the size of the electoral district and as such it does not vary across elections. ${ }^{9}$ To say, then, that all elections in a specific district are equally competitive would be an oversimplification. In addition, the closeness of the contest for the final seat in a given district cannot be considered a good proxy to the competitiveness of the electoral race as this final seat might have system, there is virtually no alternative to using ex post measures." Hence, following Cox (1988), we also assume that pre-election expectations are on average correct.

${ }^{8}$ The effective threshold of exclusion for a given region i is calculated as $1 /\left(S_{i}+1\right)$ where $S_{i}$ is the district magnitude (size). Clearly, in the case of FPTP with SMD (where $S_{i}=1$ ) the effective threshold of exclusion becomes $50 \%$.

${ }^{9}$ In fact the threshold of exclusion is collinear to the electoral district magnitude which is used in the literature to test the proportionality of the electoral rule. Hence, it is more a measure of the proportionality of the electoral rule rather than a direct way of measuring the exact mechanism which is the degree of competitiveness of the electoral race. 
minimal or insignificant influence in determining the overall electoral outcome and the policy formation. Moreover, this measure too -albeit in a lesser extent- also depends on the size of the electoral district. As a result, those two measures of the competitiveness of the race in a given district are also problematic.

Furthermore, both measures are not suitable for any cross-country pooled time-series regression analysis as both of them would exhibit zero variation within each country (over time). ${ }^{10}$ Nevertheless, since party platform polarization is hard to conceptualize and measure at the district level (not least because in national elections party platforms do not vary distinctively at the district level, especially within PR systems) we have no other option but to conduct our analysis at the national instead of the district level. As a result, since the goal of this paper is to highlight the polarization link in the proportionalityturnout relationship, we have decided to use the margin of electoral victory between the winner and the runner-up even in the context of multi-member PR districts as we consider it to be a better analogue than the other two presented above. This is so, because even in those countries applying a multi-member PR system, with few exceptions (such as Belgium, Netherlands, Denmark and Finland) there are usually only two big parties competing for the first place at the national level, making the situation comparable to the one with SMD. Of course, needless to say, all the above methods are far from being ideal. Nevertheless, given the purposes of this study our chosen method seems to be the most suitable.

Finally, following the literature (e.g., Andrews and Money 2009; Curini and Hino 2012, we test the number of competing parties hypothesis (H.2) using the natural logarithm of the Effective Number of Parties (ENP) index as our independent variable. ${ }^{11}$ Nevertheless our findings in all specifications do not vary significantly when we substitute the natural log with the ENP or the actual number of parties.

\footnotetext{
${ }^{10}$ This is easy to see as both of them critically depend on the average electoral district size (magnitude). Hence, any variation can only be exploited if the analysis is conducted at the electoral district and not at the country level.

${ }^{11}$ Laakso and Taagepera (1979) define the effective number of political parties as $1 / \sum_{j}\left(V_{j}\right)^{2}$.
} 


\section{Empirical results}

In this section, we present our econometric analysis and address concerns of endogeneity and bias related to our estimation. First, we estimate Model 0 in order to give a first rough estimate of the relationship between electoral rule disproportionality and voter turnout by regressing the first on the latter. ${ }^{12}$ Then we estimate Model 1 which jointly tests the two hypotheses that correspond to the links already identified by previous studies as determinants of turnout: the degree of competitiveness of the electoral race, measured by the margin of victory (H.2), and the size of the party-system, measured by the effective number of competing parties (H.3). That is, Model 1 serves as our benchmark since most of the literature tests these two hypotheses simultaneously (e.g. Jackman 1987; Selb 2009; Powell 2000; Blais and Carty 1990; Blais and Dobrzynska 1998; Jackman and Miller 1995). According to H.2, we expect $\beta_{2}<0$, as less competitive electoral races (higher electoral victory margins) reduce the chance of a voter being pivotal and hence, should suppress turnout. From H.3, we also expect $\beta_{3}>0$, as a larger number of parties is believed to lead to higher turnout through the channel of better representation of voters' preferences. Formally, we estimate the following equation:

$$
\text { Tournout }_{i t}=\beta_{0}+\beta_{2} * \operatorname{Margin}_{i t}+\beta_{3} * E N P_{i t}+\mathbf{X}_{i t}^{\prime} * \gamma+\lambda_{t}+\alpha_{i}+\epsilon_{i t}
$$

where $\lambda_{t}$ and $\alpha_{i}$ are year- and country-specific dummies (fixed effects) and $\mathbf{X}_{i t}^{\prime}$ is a vector that includes other control variables such as: a dummy variable to indicate frequency of coalition governments (coalition habits dummy), the number of parties participating in government/cabinet and its interaction, the type of political regime (presidentialism vs. parliamentarianism), the degree of institutional constraints, the years of consolidated democracy and a dummy variable indicating government change. Apart from fully

\footnotetext{
${ }^{12}$ To control for the disproportionality of the electoral rule we introduce a dummy variable that takes the value of 1 if the country implements a FPTP rule (the most disproportional one) and zero otherwise (that is, in the case of list-PR or mixed-PR systems). This is admittedly a very crude measure of electoral rule (dis)proportionality. Therefore, as we introduce our instrumental variables (IV) estimations, we also introduce two more elaborate measures of disproportionality.
} 
exploiting the structure of our data, one additional reason that necessitates the use of unit-specific (country) fixed effects is to account for any time-invariant country-specific characteristic (e.g. institutional arrangements such as compulsory voting laws) that can affect voter turnout. Nevertheless, for comparison purposes, we also present the estimates of equation (1) without the inclusion of controls or country-specific fixed effects.

In Model 2, we introduce our key explanatory variable (platform polarization) in order to account for the additional link between disproportionality and turnout (H.1). That is in addition to the other two previous explored links (competitiveness of the race and number of parties) that were tested via hypotheses H.2 and H.3, in this model we test all three hypotheses simultaneously. Formally, we estimate the following equation:

$$
\text { Turnout }_{i t}=\beta_{0}+\beta_{1} \text { Polarization }_{i t}+\beta_{2} * \text { Margin }_{i t}+\beta_{3} * E N P_{i t}+\mathbf{X}_{i t}^{\prime} * \gamma+\lambda_{t}+\alpha_{i}+\epsilon_{i t}
$$

We also estimate two additional versions of the above model: one using the log of ENP to control for H.3 (Model 2.a) and one where we replace the Dalton index (DI) of polarization with the MDP one (Model 2.b). Table 2 presents the results of estimating Models 1 and 2 .

\subsection{OLS results}

In the first three columns of Table 2, we present the results of Model 0 that should not be given any causal interpretation by any means. They are just intended to show the broad picture and highlight the stylized fact that many others in the literature have pointed to. That is, less (more) proportional electoral rules suppress (increase) voter turnout. Thus, it is no surprise that this well-established pattern emerges quite strongly (all the coefficients are statistically significant at the conventional $5 \%$ level) from our own estimates as well.

In the remaining columns (4-8) we explicitly test for the links through which electoral rule disproportionality affects voter turnout, as we have previously hypothesized. 
TABLE II: OLS REGRESSIONS ON THE EFFECT OF ELECTORAL SYSTEM DISPROPORTIONALITY ON VOTER TURNOUT (1960-2007)

\begin{tabular}{|c|c|c|c|c|c|c|c|c|}
\hline $\begin{array}{l}\text { Dependent Variable } \\
\text { Explanatory Variables }\end{array}$ & \multicolumn{8}{|c|}{ Voter Turnout (in \%) } \\
\hline $\begin{array}{l}\text { First-Past-The-Post }(F P T P) \text { rule } \\
(\text { dummy variable }=1)\end{array}$ & $\begin{array}{r}-12.320 \\
(6.216)^{*}\end{array}$ & $\begin{array}{l}-3.584 \\
(1.524)^{\text {*k }}\end{array}$ & $\begin{array}{r}-4.133 \\
(1.179)^{* * *}\end{array}$ & & & & & \\
\hline (H.1) Polarisation (Dalton index) & $-\because$ & $\because-$ & $-\because$ &.- &.- & $\begin{array}{r}0.316 \\
(0.448)\end{array}$ &.-- & $\begin{array}{r}0.083 \\
(0.576)\end{array}$ \\
\hline (H.1) Polarisation (MDP index) &.- &.-- & $-\cdot$ &.- &.- &.- & $\begin{array}{r}-0.106 \\
(0.390)\end{array}$ & -- \\
\hline (H.2) Margin of victory (in \%) &.- & -- & $-\cdot-$ & $\begin{array}{r}-0.067 \\
(0.067)\end{array}$ & $\begin{array}{l}-0.107 \\
(0.051)^{*}\end{array}$ & $\begin{array}{r}-0.070 \\
(0.069)\end{array}$ & $\begin{array}{r}-0.065 \\
(0.067)\end{array}$ & $\begin{array}{l}-0.108 \\
(0.051)^{*}\end{array}$ \\
\hline (H.3) Log Effective Num. Parties &.-- & -- & -- & $\begin{array}{r}0.380 \\
(2.978)\end{array}$ & $\begin{array}{r}-2.581 \\
(3.325)\end{array}$ & $\begin{array}{r}0.284 \\
(2.982)\end{array}$ & $\begin{array}{r}0.489 \\
(3.049)\end{array}$ & $\begin{array}{r}-2.621 \\
(3.251)\end{array}$ \\
\hline Country FE? & No & Yes & Yes & Yes & Yes & Yes & Yes & Yes \\
\hline$R^{2}$ & 0.27 & 0.93 & 0.95 & 0.93 & 0.95 & 0.93 & 0.93 & 0.95 \\
\hline$N$ & 307 & 307 & 235 & 302 & 235 & 302 & 302 & 235 \\
\hline
\end{tabular}

Columns 4 and 5 present the estimates of Model 1 (as in e.g., Selb 2009) that tests the two "traditional" hypotheses: the competitiveness of the race (H.2) and the number of parties (H.3) hypotheses. As our results show, we find no support for H.3 (which is also the case in much of the previous literature, e.g., Blais and Aarts 2006; Powell 2000) but more surprisingly we only find limited support for H.3 under some specifications (small sample with controls) contrary to what previous literature has suggested (e.g. Selb 2009).

In columns 6-8, we introduce our key explanatory variable (platform polarization) and present the estimates of Models 2.a and 2.b in order to test our primary hypothesis (H.1) jointly with the remaining two. Again, in almost all specifications, we fail to find statistically significant support for any of our three hypotheses, including our primary one on the effect of electoral rules on turnout via platform polarization. That is, even though electoral rule disproportionality appears to be strongly correlated with voter turnout (see columns 1-3) none of the proposed mechanisms seems to be able to provide a clear link that connects proportionality and turnout. Moreover, even in those specifications that we do find some support for the competitiveness hypothesis (H.2) the estimates are not 
politically significant. Yet, we do not think that this failure of confirming any of the three hypotheses is very surprising or particularly problematic, since those simple OLS results should be interpreted with some caution. That is, there are reasons to believe that those results suffer from various sources of bias (e.g., omitted variables or endogeneity).

One such source of bias can be an omitted variable that can affect both voter turnout and also polarization at the same time. For instance, as previous literature has suggested the personal traits or characteristics of a candidate can be very influential both in the ability of its party to mobilize voters and also on the degree of perceived platform polarization. One can imagine that there can be a series of other unobservable or hard to measure parameters which can influence both polarization and voter turnout. As a result, omitted variables place the first important challenge to our OLS estimates.

In addition to omitted variable bias, as recent theoretical and empirical evidence suggests (e.g., Matakos et al. 2013), platform polarization also depends on the number of competing parties, which in turn, can be endogenously determined by the (dis)proportionality of the electoral rule (Duverger, 1954). Since empirical evidence (Gallagher, 1991) and theoretical literature (Duverger, 1954) suggest that electoral rules may also affect polarization through the structure of the party-system (e.g., number of parties) not accounting for this link and failure to test it jointly can result in a biased estimation (for details e.g., Cox 1990). Hence, this can be an additional explanation on the failure of obtaining statistically significant results under the OLS specification. Finally, there is always a very good chance that the OLS results also suffer from endogeneity. To put it simply, if voter turnout at year $t$ is serially correlated with turnout in year $t-1$, then in the very likely case that polarization in year $t$ also depends on past electoral outcomes (and turnout) it is obvious that a reverse causal link can be established between turnout and polarization.

For all the above reasons, we estimate equation (2) by introducing an IV to instrument for platform polarization. Moreover, econometric and technical reasons aside, there is a purely theoretical reason that justifies the use of a Two-Stage Least Squares (TSLS) specification. As the reader may recall, our argument on the possible link between pro- 
portionality and turnout is a two-step one. As we have shown, platform polarization is the mean through which electoral rules affect voter turnout. Hence, our theoretical model as well points to the direction of a TSLS specification by instrumenting platform polarization with the degree of electoral rule disproportionality.

\subsection{Instrumental Variable Regressions: Electoral Rule Dispro- portionality}

When it comes to the choice of our instrumental variable, our theoretical section can be quite instructive. As we have shown in Proposition 1 platform polarization is directly related to the disproportionality of the electoral rule: the more (dis)proportional the rule is the (lower) higher the degree of platform polarization. Hence, electoral rules constitute a good candidate for an instrumental variable (IV). Moreover, apart from the theoretical considerations, there are other reasons of econometric nature that make electoral rules both a relevant (as Proposition 1 dictates) and also a valid instrument. Electoral rule is a slow-moving, sluggish institutional variable. As a result, is very unlikely that is affected by voter turnout which addresses our endogeneity concern. Moreover, after controlling for the number of parties as we do, there is no other channel via which electoral rule disproportionality can affect platform polarization other than the one we have specified above. A similar argument is also made in Persson et al. (2007) where, in analogous fashion, they employ electoral rule type as an instrument for electoral fragmentation. ${ }^{13}$ Hence, we conclude that our IV is not only relevant but also valid. Later in this section, we will resume the discussion behind the reasons that dictate the choice of electoral rule disproportionality as our IV. But first, we need to describe how we will operationalize the measurement of electoral rule disproportionality.

\section{Measuring Electoral Rule Disproportionality}

\footnotetext{
${ }^{13}$ In many ways there is a clear analogy on how Persson et al. (2007) measure the index of electoral fragmentation with our own measurement of platform polarization using the Dalton Index as both indices capture the degree of vote share (or ideological) dispersion among different political parties.
} 
We construct the majoritarian bias parameter of the electoral rule $n$, as defined in our theoretical section. By combining data from two different sources (Armingeon et al., 2012; Carey, 2012) we are able to estimate the bias parameter for twenty countries in our sample by applying the formula proposed by Taagepera (1986):

$$
n=[\log (V) / \log (S)]^{(1 / M)}
$$

where $V$ the total number of voters, $S$ is the total number of parliamentary seats in the legislature and $M$ is the average electoral district size (magnitude). Estimating this bias parameter permits a tight fit between our model's predictions and the empirical estimation. As we note in previous work (Matakos et al., 2013) "[an] additional advantage of using this variable, given that the electoral rule is a sluggish institutional variable, is that it is continuous and exhibits some within country variation, therefore allowing for both within and cross-country comparisons."

As a robustness check, we repeat our estimates using an alternative measure of electoral rule disproportionality as an instrument for platform polarization: a binary variable that takes the value of one whenever the FPTP rule with SMD is applied and zero otherwise. The rational for using a binary variable as our instrument is as follows. Given that this version of our IV (electoral rule dummy) either does not vary at all, or exhibits minimal variation within each unit (country), this allows us to effectively insulate our estimates from any additional concerns over endogeneity and ensure that the exclusion restriction (for our IV) is satisfied. For instance, one such concern might be that polarization could also affect the choice of electoral rules (for a detailed discussion e.g., Matakos et al. 2013). Nevertheless, the sluggish or unit-invariant instrumental variable (electoral rule dummy) addresses any such concerns as, with the exception of three countries, it does not vary over time. For this reason, we present all our subsequent estimates under both specifications. Formally, in our TSLS model (Model 3) we estimate the following 
two equations:

$$
\text { Polarization }_{i t}=b_{0}+\pi_{1} Z_{i t}+b_{2} * \text { Margin }_{i t}+b_{3} * E N P_{i t}+\mathbf{X}_{i t}^{\prime} * \gamma+\lambda_{t}+\alpha_{i}+\xi_{i t}
$$

and

$$
\text { Turnout }_{i t}=\beta_{0}+\beta_{1} \widehat{\operatorname{Polar}}_{i t}+\beta_{2} * \operatorname{Margin}_{i t}+\beta_{3} * E N P_{i t}+\mathbf{X}_{i t}^{\prime} * \gamma+\lambda_{t}+\alpha_{i}+\epsilon_{i t}
$$

Equation (3) specifies our first stage OLS regression, where $Z_{i t}$ is our instrument (electoral rule disproportionality) either in the form of the majoritarian bias parameter $n$ (Model 3.a) or in the form of a dummy variable (Model 3.b) indicating the presence of FPTP system $\left(Z_{i t}=1\right.$ and 0 otherwise). Remember that we measure polarization applying two distinct indices: the Dalton Index (DI) and the Most Distant Platform (MDP) one. That is, overall we estimate four alternative first stage specifications with all of them yielding identical results. Equation (4) specifies the second stage regression where replace Polarization $i t$ with its predicted value $\left(\widehat{\text { Polar }}_{i t}\right)$ from equation $(3)$. As argued before, our theoretical results suggest that we should expect $\pi_{1}<0$, that is more disproportional rules result in less polarization. Similarly, we also expect the coefficient on Polarization in the second-stage regression to be positive $\left(\beta_{1}>0\right)$. That is, according to our hypothesized relationship, increased platform divergence (more polarization) may reduce the indifference effect thus causing an increase in voter turnout. ${ }^{14}$ We present our IV regression estimates (together with the first-stage regression results) in Table 3.

We also estimate the reduced form version of Model 3, using the natural log of the average electoral district magnitude as an additional alternative measure of our main explanatory variable, electoral rule disproportionality. ${ }^{15}$ Formally, we estimate the following

\footnotetext{
${ }^{14}$ That is, if one is to run the reduced form regressions (as we do in Table 4) the direct effect of electoral rule disproportionality (via our proposed mechanism) on voter turnout should be negative. That is, more disproportional (proportional) rules supress (increase) voter turnout, exactly as we have hypothesized.

${ }^{15}$ An additional alternative measure of electoral rule disproportionality is the natural log of the average electoral district magnitude (as in Carey and Hix 2011). The idea behind its usage is that larger district magnitude reduces the effective threshold of exclusion, hence, making the electoral system more proportional (Taagepera, 1986). We employ this variable only in the reduced form regressions presented
} 
TABLE III: 2SLS REGRESSIONS ON THE EFFECT OF POLARIZATION (INSTRUMENTED BY ELECTORAL RULE DISPROPORTIONALITY) ON VOTER TURNOUT

\begin{tabular}{|c|c|c|c|c|c|c|c|c|}
\hline \multirow{3}{*}{$\begin{array}{l}\text { Dependent Variable } \\
\text { Explanatory Variables }\end{array}$} & \multicolumn{8}{|c|}{ Voter Turnout (\%) } \\
\hline & \multicolumn{4}{|c|}{ Model 3.a } & \multicolumn{4}{|c|}{ Model 3.b } \\
\hline & (1) & (2) & (3) & (4) & (5) & (6) & (7) & (8) \\
\hline (H.1) Polarization (Dalton Index) & $\begin{array}{r}5.293 \\
(1.939)^{* * * *}\end{array}$ & $\begin{array}{r}9.083 \\
(4.093)^{* *}\end{array}$ & $\begin{array}{r}2.687 \\
(0.725)^{* * * *}\end{array}$ & $\begin{array}{r}5.930 \\
(1.523)^{* * *}\end{array}$ & $-\because-$ & $-\because-$ & $-\because-$ & $-\because-$ \\
\hline (H.1) Polarization (MDP Index) & $-\cdot-$ &.-- & $-\cdot-$ & -- & $\begin{array}{r}3.840 \\
(1.407)^{* * * *}\end{array}$ & $\begin{array}{r}5.308 \\
(1.752)^{* * * *}\end{array}$ & $\begin{array}{r}2.087 \\
(0.588)^{* * *}\end{array}$ & $\begin{array}{r}3.945 \\
(0.925)^{* * *}\end{array}$ \\
\hline (H.2) Margin of victory (in \%) & $\begin{array}{r}-0.090 \\
(0.088)\end{array}$ & $\begin{array}{r}-0.192 \\
(0.085)^{* *}\end{array}$ & $\begin{array}{r}-0.088 \\
(0.068)\end{array}$ & $\begin{array}{r}-0.162 \\
(0.066)^{* * *}\end{array}$ & $\begin{array}{r}-0.116 \\
(0.088)\end{array}$ & $\begin{array}{r}-0.188 \\
(0.086)^{* * *}\end{array}$ & $\begin{array}{r}-0.106 \\
(0.067)\end{array}$ & $\begin{array}{r}-0.167 \\
(0.072)^{* *}\end{array}$ \\
\hline (H.3) Log Effective Num. of Parties & $\begin{array}{r}-2.818 \\
(3.438)\end{array}$ & $\begin{array}{r}-6.961 \\
(5.218)\end{array}$ & $\begin{array}{r}-0.437 \\
(2.691)\end{array}$ & $\begin{array}{r}-5.441 \\
(3.327)\end{array}$ & $\begin{array}{l}-5.727 \\
(4.582)\end{array}$ & $\begin{array}{l}-10.742 \\
(4.284)^{\text {*k* }}\end{array}$ & $\begin{array}{r}-1.760 \\
(3.161)\end{array}$ & 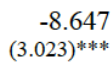 \\
\hline \multirow[t]{3}{*}{ Adjusted $R^{2}$} & 0.88 & 0.78 & 0.91 & 0.88 & 0.89 & 0.86 & 0.91 & 0.90 \\
\hline & \multicolumn{8}{|c|}{ First-Stage OLS Regressions } \\
\hline & \multicolumn{4}{|c|}{ Polarization (measured by the Dalton Index) } & \multicolumn{4}{|c|}{ Polarization (measured by the MDP Index) } \\
\hline $\begin{array}{l}\text { Instrumental Variable } \\
\text { Majoritarian bias of ER ( } n)\end{array}$ & $\begin{array}{l}-0.528 \\
(0.148)^{* * * *}\end{array}$ & $\begin{array}{r}-0.346 \\
(0.168)^{* * *}\end{array}$ &.-- & $-\therefore$ & $\begin{array}{r}-0.728 \\
(0.192)^{* * * *}\end{array}$ & $\begin{array}{r}-0.592 \\
(0.187)^{* * * *}\end{array}$ &.- & $-\because-$ \\
\hline First-Past-the-Post ER (Dummy = 1) &.-- &.-- & $\begin{array}{r}-1.601 \\
(0.225)^{* * *}\end{array}$ & $\begin{array}{r}-1.200 \\
(0.303)^{* * *}\end{array}$ &.-- &.-- & $\begin{array}{r}-2.061 \\
(0.286)^{* * *}\end{array}$ & $\begin{array}{r}-1.803 \\
(0.364)^{* * *}\end{array}$ \\
\hline $1^{\text {st }}$ Stage $F$-score (on excluded IV) & 12.79 & 4.27 & 50.84 & 15.65 & 14.45 & 10.04 & 51.83 & 24.50 \\
\hline $1^{\text {st }}$ Stage $R^{2}$ & 0.42 & 0.42 & 0.40 & 0.43 & 0.62 & 0.64 & 0.56 & 0.64 \\
\hline Other Controls & No & Yes & No & Yes & No & Yes & No & Yes \\
\hline Year dummies & Yes & Yes & Yes & Yes & Yes & Yes & Yes & Yes \\
\hline Country Fixed Effects & Yes & Yes & Yes & Yes & Yes & Yes & Yes & Yes \\
\hline$N$ & 253 & 235 & 302 & 235 & 253 & 235 & 302 & 235 \\
\hline
\end{tabular}

equation:

Turnout $_{i t}=\beta_{0}+\delta_{1}$ Disproportionality $_{i t}+\beta_{2} * \operatorname{Margin}_{i t}+\beta_{3} * E N P_{i t}+\mathbf{X}_{i t}^{\prime} * \gamma+\lambda_{t}+\alpha_{i}+\eta_{i t}$

Clearly, since $\beta_{1}=\delta_{1} / \pi_{1}$, we expect $\delta_{1}<0$ as more disproportional rules lead to a decrease in polarization $\left(\pi_{1}<0\right)$ and in turn, a decrease in polarization should lead to a decrease in turnout $\left(\beta_{1}>0\right)$. We present the estimates of the reduced form equation (5) above in Table 4.

Our estimates presented in Table 3 provide strong support in favour of our first hypothesis (indifference): increased platform polarization (when measured by the Dalton Index) leads to a sizeable and statistically significant (at any conventional level) increase in voter turnout. The coefficient estimate, which ranges from 2.7 to 9.1, indicates that a one standard deviation (0.8) increase in polarization index is associated with a 4 to in Table 4. 
7 percentage points increase in voter turnout. This result is not only statistically but also politically significant. Moreover, our findings are robust to alternative specifications (including more controls as in columns 2 and 4) and also to the use of alternative IVs (as in columns 3 and 4 where we use the dummy FPTP variable as our instrument). Furthermore, notice that in all cases the first-stage OLS estimates on the effect of the electoral rule on platform polarization are statistically significant (at any conventional level), large in magnitude and negative, as expected (the coefficient range is from -0.35 to -0.52 and from -1.2 to -1.6 respectively when the two different IVs are employed). ${ }^{16}$ That is, our first-stage regressions confirm the hypothesized relationship between electoral rule disproportionality and platform polarization (e.g., Cox 1990; Matakos et al. 2013 which implies that our IV is certainly relevant. In addition, in all but one case, the first-stage F-statistic on the excluded IV is well above the critical threshold value (of 10) that is suggested by the literature. Hence, we conclude that our instrument is also a valid one.

The same image also re-emerges when we replace the Dalton with the MDP index of platform polarization. Albeit the coefficients are slightly smaller in magnitude, they are still positive (ranging from 2.1 to 5.3 ) and statistically significant at any conventional level. The smaller magnitude is nevertheless expected and consistent with our hypothesis of abstention due to indifference. Clearly, the MDP index measures the platform divergence of the two most extreme parties which sometimes can be marginal or friction parties and therefore less relevant in the eyes of prospective voters who might care less about the platforms of such frictional parties who play little role in policy formation. Similarly, the coefficients on the first-stage regressions are again negative (with a range from -0.6 to -2.1) and statistically significant at any conventional level in all specifications (as are the first-stage F-statistics). Thus, our IV results conclusively provide strong evidence in favour of our first hypothesis. The same is also true if one also looks at the reduced form regression results presented in Table 4 .

\footnotetext{
${ }^{16}$ Our first-stage estimates can be interpreted as saying that a change in the electoral rule from pure PR to an FPTP system with SMD can be associated with almost two standard deviations increase in the polarization index.
} 
TABLE IV: REDUCED FORM OLS REGRESSIONS OF THE 2-SLS MODEL (TABLE III) REPLACING POLARIZATION WITH ELECTORAL RULE DISPROPORTIONALITY

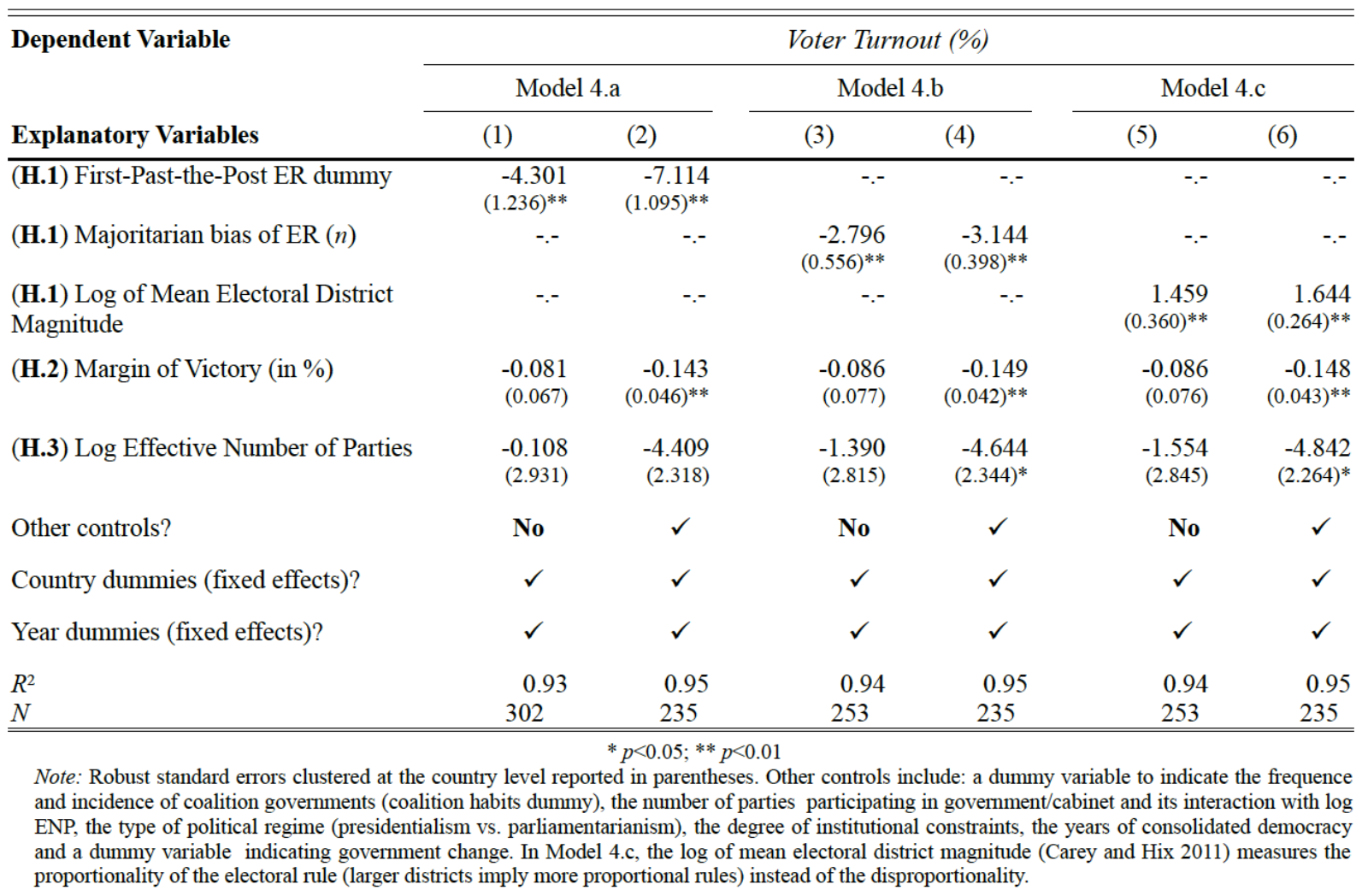

\subsection{IV results}

Concerning the remaining two hypotheses, we do find some support for the competitiveness pivotality one (H.2) as our results indicate that the closer a race is the higher is voter turnout. In all specifications the coefficient is negative (ranging from -0.1 to -0.2 ) yet it fails to be statistically significant even at the $10 \%$ level in half of those (nonetheless it is statistically significant at the $5 \%$ level in those specifications where additional control variables are included). The point estimates on the coefficient indicate that a decrease in the closeness of the race by 10 percentage points is associated with an increase in turnout by 1-2 percentages points. This is certainly a non-negligible effect. Yet, as our estimates indicate this mechanism that was previously championed by the literature does not appear to be the most predominant one. It rather seems that the missing link that we have uncovered through platform polarization can substantially explain the proportionality-turnout nexus. 
Finally, we fail to find any support for our third hypothesis (party-system size) under almost all alternative specifications. Moreover, in those two instances (columns 7 and 8) where the coefficient on the ENP variable is statistically significant, its sign is the opposite than what was hypothesized. That is, contrary to H.3 an increase in the effective number of parties is associated with a decrease in voter turnout (coefficient ranges from -10.7 to -8.7). While somehow surprising, this finding is in accordance with previous findings in the literature (e.g., Powell 2000; Blais and Aarts 2006) which suggest that the positive relationship between proportional electoral rules and turnout, a quite robust empirical regularity, is not because there are more parties but, in fact, it could be despite the presence of more parties. As a result, we are left with the conclusion that the platform polarization mechanism seems to be the most robust amongst the three proposed links that connects electoral rule (dis)proportionality and voter turnout.

\section{Concluding Remarks}

Our study has uncovered a missing link in the proportionality-turnout nexus. We have shown that as more majoritarian (less proportional) rules tend to generate centripetal forces and drive parties' platform to converge (less polarization) voters become indifferent between the options available to them and thus are more inclined to abstain. Hence, there appears to be a strong and positive relationship between polarization and turnout.

In light of this finding, perhaps a less gloomy view on the recent trend of declining turnout in much of the industrialized world is permitted. If higher turnout is an outcome of more polarization (as our causal IV estimates indicate) then, the recent decline in turnout observed in much of the western world could also be a positive sign of more political moderation. Perhaps voters feel less compelled to vote when all alternative seem to be converging, which in turn is no reason for excessive worry but rather a signal of political maturity. That is, in more mature democracies, which are characterized by more moderation and less tensions, voters realize that old-fashioned partisan politics cannot 
have a dramatic impact in their lives. This need not necessarily be a negative thing as mature democracies tend to develop other channels of political participation and civic engagement than simple participation in partisan politics and elections. Contrary to that, it comes as no surprise that in countries were political tension and polarization is high voter turnout is also extremely high. ${ }^{17}$ It is exactly the case that in less mature democracies political polarization and tension are very high and thus voters are more inclined to participate in partisan politics. Hence, as our work indicates low voter turnout rates do not constitute a good proxy for the quality of a democratic polity. It is therefore important to devote more effort into identifying and understanding the causal factors that drive voter turnout in order to be able to identify whether increased turnout is an outcome of more electoral competition (positive) or increased polarization (negative).

Finally, our research can also speak to another puzzle in politics: the declining rate of voter turnout in the majority of EU states (both in their national and also panEuropean elections). As further European integration tends to foster convergence in a series of different policies it is not surprising that major European political parties have converged (in terms of their political platforms) with each other. In turn, if one is to believe our link between platform convergence and turnout, this can potentially lead to higher rates of abstention due to indifference as the major political parties, increasingly so, look alike as a result of deeper European integration.

\section{Appendix}

Proof of proposition 1. The proof of this proposition can be split in five distinct parts.

Part 1. Since the behavior of voters is unambiguous in this model we should focus on understanding the dynamics which determine candidate behavior. Given $n$ we have that party $L$ decides $p_{L}$ in order to maximize

\footnotetext{
${ }^{17}$ For example in the 2014 Turkish local elections, which were characterized by an unprecedented level of polarization and the political discourse was dominated by issues of national political agenda, voter turnout reached a staggering (by any standard) $91 \%$.
} 
$u_{L}\left(\hat{p}\left(p_{L}, p_{R}, n\right)\right)=-\left(\pi_{L}-\hat{p}\left(p_{L}, p_{R}, n\right)\right)^{2}=-\hat{p}\left(p_{L}, p_{R}, n\right)^{2}$

while party $R$ decides $p_{R}$ in order to maximize

$u_{R}\left(\hat{p}\left(p_{L}, p_{R}, n\right)\right)=-\left(\pi_{R}-\hat{p}\left(p_{L}, p_{R}, n\right)\right)^{2}=-\left(1-\hat{p}\left(p_{L}, p_{R}, n\right)\right)^{2}$.

Hence, $u_{L}\left(\hat{p}\left(p_{L}, p_{R}, n\right)\right)$ is strictly decreasing in $\hat{p}\left(p_{L}, p_{R}, n\right)$ for every $\hat{p}\left(p_{L}, p_{R}, n\right)$ between zero and one and $u_{R}\left(\hat{p}\left(p_{L}, p_{R}, n\right)\right)$ is strictly decreasing in $\hat{p}\left(p_{L}, p_{R}, n\right)$ for every $\hat{p}\left(p_{L}, p_{R}, n\right)$ between zero and one. Letting aside mixed strategies, this means that our two player game is strategically equivalent to the two-player zero sum game in which one player (party $L)$ decides $p_{L}$ in order to minimize $\hat{p}\left(p_{L}, p_{R}, n\right)$ and the other player (party $R$ ) decides $p_{R}$ in order to minimize $\hat{p}\left(p_{L}, p_{R}, n\right)$. Therefore, if we characterize the equilibrium set of this zero-sum game we will have the equilibrium set of the game we are interested in.

Part 2. We notice that in equilibrium it has to be the case that $\hat{p}\left(p_{L}^{*}, p_{R}^{*}, n\right)=\frac{1}{2}$. As said our game is strategically equivalent to the described zero-sum game. Therefore, it has to be the case that the equilibrium implemented policy (which coincides with the value of the zero-sum game) is unique; all equilibria should deliver the same implemented policy. Imagine that in this unique equilibrium implemented policy is such that $\hat{p}\left(p_{L}^{*}, p_{R}^{*}, n\right)<\frac{1}{2}$. If party $R$ deviates and proposes a platform $1-p_{L}^{*}$ it will switch the implemented policy to $\frac{1}{2}$; this is obviously profitable for party $R$ as it will bring the implemented policy nearer to its ideal policy. An equivalent argument rule out possibility of $\hat{p}\left(p_{L}^{*}, p_{R}^{*}, n\right)>\frac{1}{2}$. Therefore, in equilibrium it has to be that $\hat{p}\left(p_{L}^{*}, p_{R}^{*}, n\right)=\frac{1}{2}$.

Part 3. If the equilibrium set is non-empty then an equilibrium should exist such that $p_{L}^{*}<\frac{1}{2}<p_{R}^{*}=1-p_{L}^{*}$. If an equilibrium exists and $p_{L}^{*} \geq \frac{1}{2}$ then $\hat{p}\left(p_{L}^{*}, p_{R}^{*}, n\right)=$ $\frac{1}{2}$ suggests that $p_{R}^{*} \leq \frac{1}{2}$. This implies that a) if $p_{R}^{*}=\frac{1}{2}$ party $L$ can deviate to the policy $p_{L}=0$ and, given our parameters restrictions, receive some votes and thus induce $\hat{p}\left(0, \frac{1}{2}, n\right)<\frac{1}{2}$ and that b) if $p_{R}^{*}<\frac{1}{2}$ party $L$ can deviate to the policy $p_{L}=p_{R}^{*}$ and thus induce $\hat{p}\left(p_{R}^{*}, p_{R}^{*}, n\right)<\frac{1}{2}$. This rules out possibility of an equilibrium such that $p_{R}^{*} \leq \frac{1}{2}$ too. Moreover, since our game is strategically equivalent to a zero-sum game it has to be the case that every equilibrium strategy is a minimaximizer strategy and the other 
way round. This along with the fact that our game also satisfies a symmetry notion $(\hat{p}(\mu, \nu, n)=1-\hat{p}(1-\nu, 1-\mu, n))$ suggests that if $p_{L}^{*}$ is a minimaximizer strategy for party $L$ then $1-p_{L \text { : }}^{*}$ must be a minimaximizer strategy of party $R$.

Part 4. We observe that when $p_{R}>\frac{1+v}{2}$ there exists $\varepsilon>0$ such that $\hat{p}\left(p_{L}, p_{R}, n\right)$ is differentiable in $p_{L} \in\left(1-p_{R}-\varepsilon, 1-p_{R}+\varepsilon\right)$. Routine algebraic manipulations show that $\left.\frac{\partial u_{L}\left(\hat{p}\left(p_{L}, p_{R}, n\right)\right)}{\partial p_{L}}\right|_{p_{R}=1-p_{L}}=0$ if and only if $p_{L}^{*}=\frac{-1+2 n-\sqrt{1-4 v n}}{4 n}<\frac{1-v}{2}$ (in which case $\left.p_{R}^{*}=1-\frac{-1+2 n-\sqrt{1-4 v n}}{4 n}=\frac{1+2 n+\sqrt{1-4 v n}}{4 n}\right)$. That is, $\left(p_{L}^{*}, p_{R}^{*}\right)=\left(\frac{-1+2 n-\sqrt{1-4 v n}}{4 n}, \frac{1+2 n+\sqrt{1-4 v n}}{4 n}\right)$ is candidate for an equilibrium. By plotting $\hat{p}\left(p_{L}, \frac{1+2 n+\sqrt{1-4 v n}}{4 n}, n\right)$ we notice that it admits a unique minimum for any admissible pair of parameter values (see figures 3, 4 and 5) and hence $u_{L}\left(\hat{p}\left(p_{L}, \frac{1+2 n+\sqrt{1-4 v n}}{4 n}, n\right)\right)$ admits a unique maximum too. That is party $L$ has a unique minimaximizer strategy $p_{L}^{*}=\frac{-1+2 n-\sqrt{1-4 v n}}{4 n}$ which suggests that our game admits the unique equilibrium $\left(p_{L}^{*}, p_{R}^{*}\right)=\left(\frac{-1+2 n-\sqrt{1-4 v n}}{4 n}, \frac{1+2 n+\sqrt{1-4 v n}}{4 n}\right)$.

Part 5. It is straightforward that $\frac{\partial\left(p_{R}^{*}-p_{L}^{*}\right)}{\partial n}<0$ and hence the distance between the equilibrium platforms is decreasing in the level of disproportionality of the electoral rule.

Proof of proposition 2. This is straightforward as $\frac{\partial T^{*}(n)}{\partial n}<0$ for every strictly positive and admissible value of the parameters. 


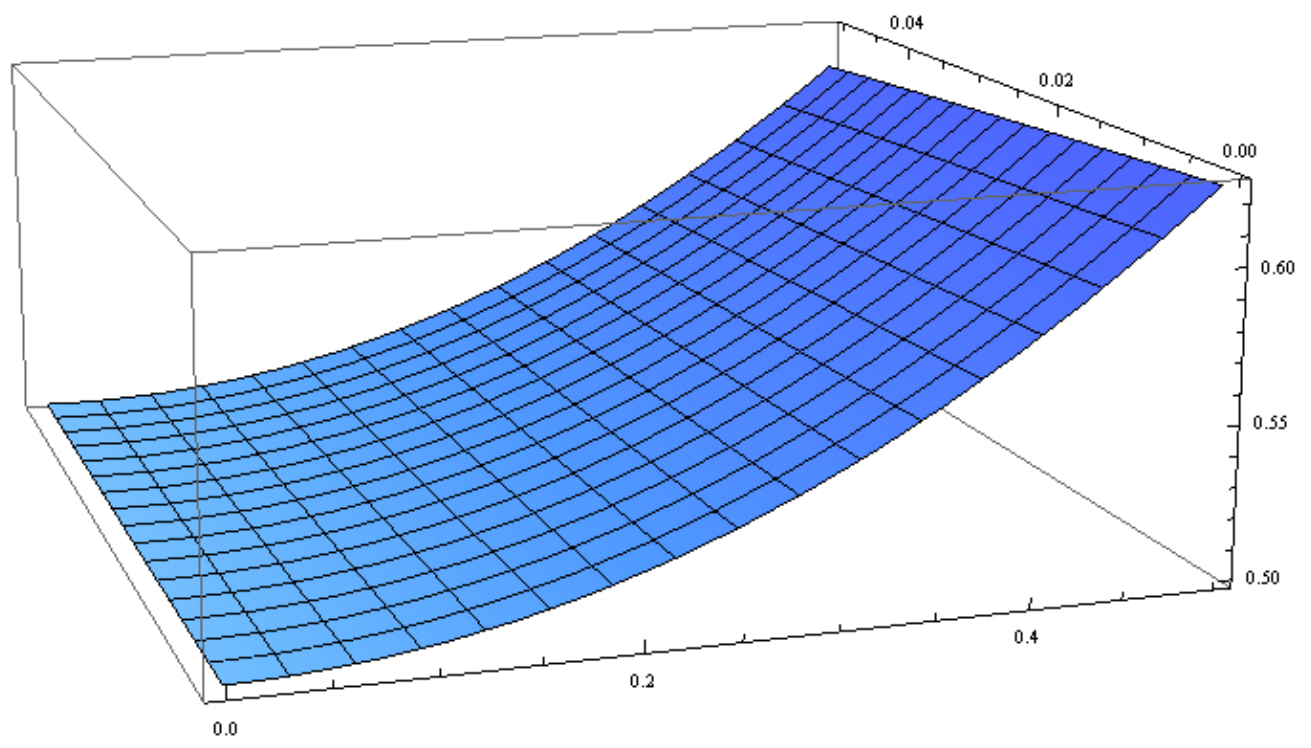

Figure 3: Implemented policy -height- as a function of the policy platform of party $L, p_{L} \in$ $[0,1 / 2)$-length- and abstention parameter $v \in[0,0.05]$-width- when $p_{R}=\frac{1+2 n+\sqrt{1-4 v n}}{4 n}$ and the electoral rule is purely proportional $(n=1)$.

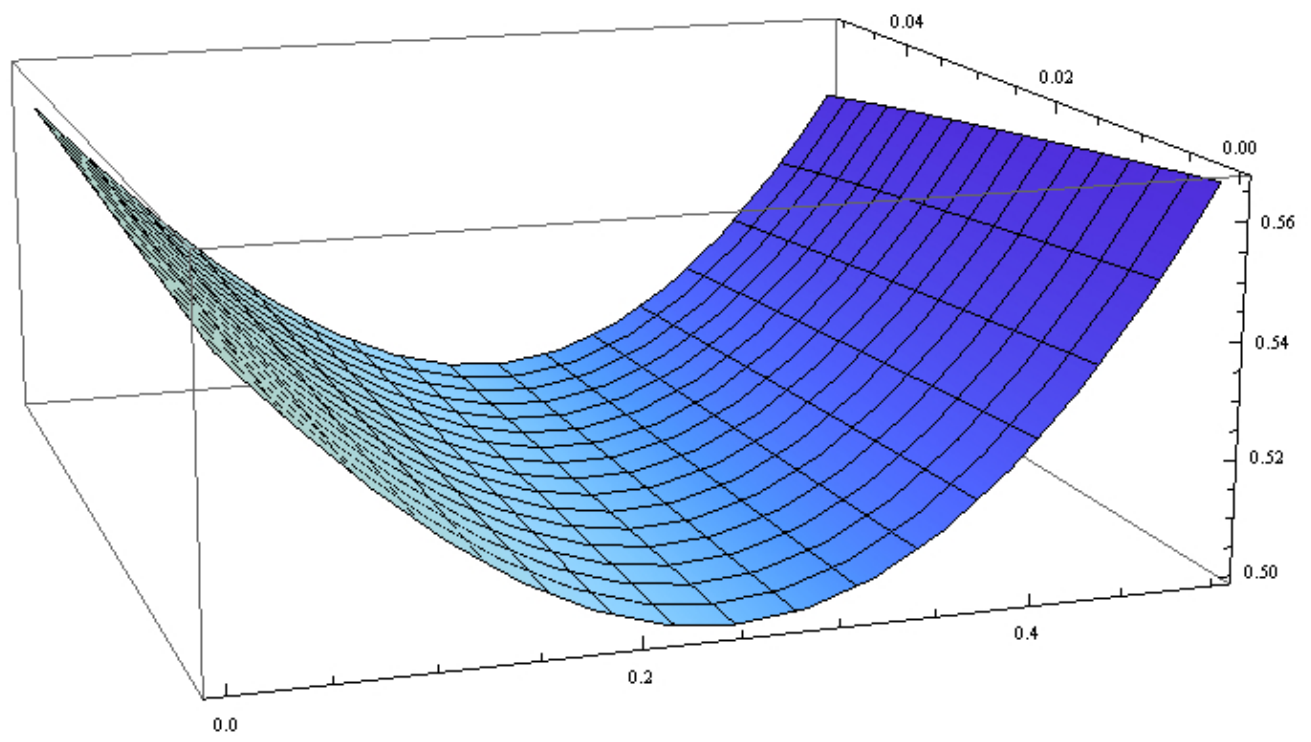

Figure 4: Implemented policy -height- as a function of the policy platform of party $L, p_{L} \in$ $[0,1 / 2)$-length- and abstention parameter $v \in[0,0.05]$-width- when $p_{R}=\frac{1+2 n+\sqrt{1-4 v n}}{4 n}$ and the electoral rule is mixed $(n=2)$. 


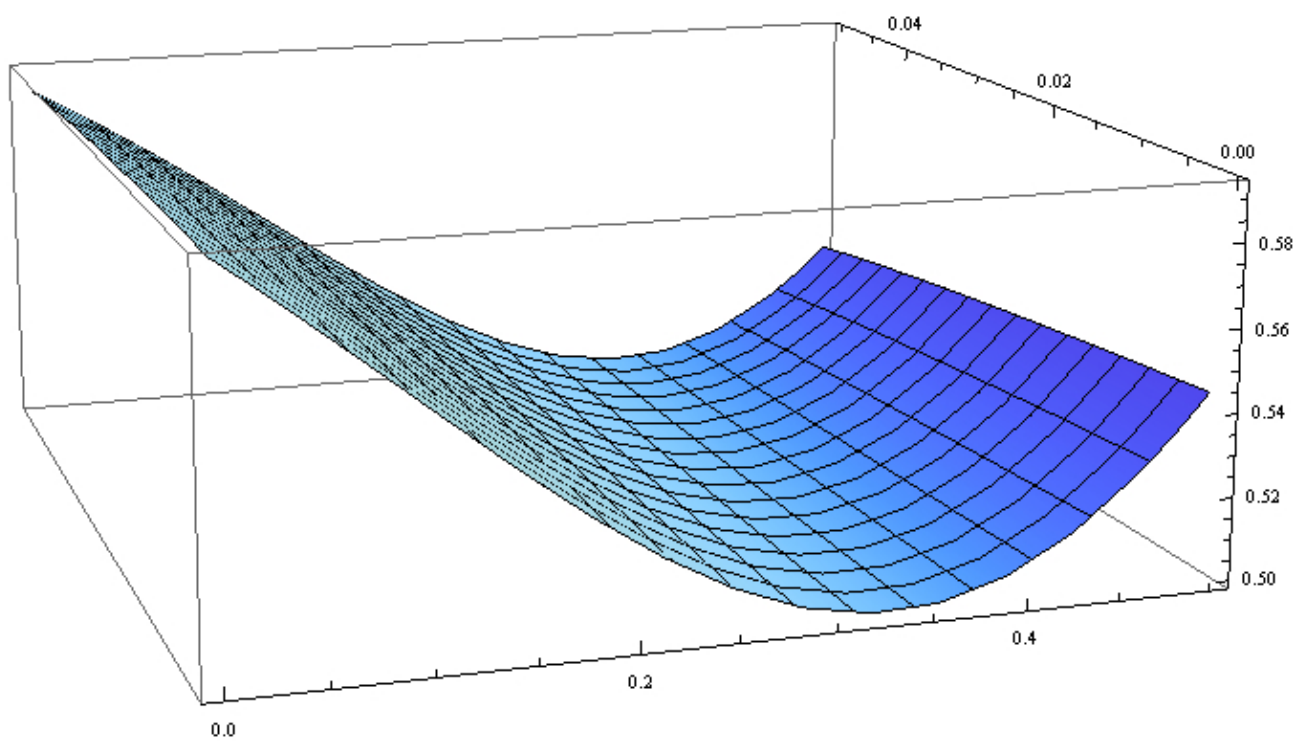

Figure 5: Implemented policy -height- as a function of the policy platform of party $L, p_{L} \in$ $[0,1 / 2)$-length- and abstention parameter $v \in[0,0.05]$-width- when $p_{R}=\frac{1+2 n+\sqrt{1-4 v n}}{4 n}$ and the electoral rule is majoritarian $(n=3)$. 


\section{References}

Adams, J., S. Merrill III, And B. Grofman (2005): A unified theory of party competition: A cross-national analysis integrating spatial and behavioral factors, Cambridge University Press.

Andrews, J. AND J. MONEY (2009): "The spatial structure of party competition: Party dispersion within a finite policy space," British Journal of Political Science, 39, 805-824.

Aragonès, E. And T. R. PAlfrey (2002): "Mixed equilibrium in a Downsian model with a favored candidate," Journal of Economic Theory, 103, 131-161.

Aragonès, E. And D. Xefteris (2012): "Candidate quality in a Downsian model with a continuous policy space," Games and Economic Behavior, 75, 464-480.

Armingeon, K., P. Potolidis, M. Gerber, And P. Leimgruber (2012): Comparative Political Data Set I(CPDS I), 1960-2010, Bern: Institute of Political Science, University of Bern.

Blais, A. (2006): "What affects voter turnout?" Annu. Rev. Polit. Sci., 9, 111-125.

Blais, A. And K. Aarts (2006): "Electoral systems and turnout," Acta Politica, 41, 180-196.

Blais, A. AND R. CARTY (1990): "Does proportional representation foster voter turnout?" European Journal of Political Research, 18, 167-181.

Blais, A. And A. Dobrzynska (1998): "Turnout in electoral democracies," European Journal of Political Research, 33, 239-262.

Budge, I. And M. McDonald (2006): "Choices Parties Define Policy Alternatives in Representative Elections, 17 Countries 1945-1998," Party Politics, 12, 451-466.

Calvert, R. (1985): "Robustness of the multidimensional voting model: Candidate motivations, uncertainty, and convergence," American Journal of Political Science, 29, 69-95.

Carey, J. M. (2012): Carey data archive.

Carey, J. M. And S. Hix (2011): "The Electoral Sweet Spot: Low-Magnitude Proportional Electoral Systems," American Journal of Political Science, 55, 383-397.

Cox, G. (1990): "Centripetal and centrifugal incentives in electoral systems," American Journal of Political Science, 34, 903-935.

Cox, G. W. (1988): "Closeness and turnout: A methodological note," The Journal of Politics, 50, 768-775.

Curini, L. AND A. Hino (2012): "Missing links in party-system polarization: How institutions and voters matter," The Journal of Politics, 74, 460-473. 
DALton, R. (2008): "The quantity and the quality of party systems party system polarization, its measurement, and its consequences," Comparative Political Studies, 41, 899-920.

De Sinopoli, F. And G. Iannantuoni (2007): "A spatial voting model where proportional rule leads to two-party equilibria," International Journal of Game Theory, $35,267-286$.

DellaVigna, S. And E. Kaplan (2007): "The Fox News effect: Media bias and voting," The Quarterly Journal of Economics, 122, 1187-1234.

Dow, J. (2011): "Party-System Extremism in Majoritarian and Proportional Electoral Systems," British Journal of Political Science, 41, 341-361.

Duverger, M. (1954): Political parties: their organization and activity in the modern state, Methuen.

Elkins, D. J. (1974): "The measurement of party competition," American Political Science Review, 682-700.

Enelow, J. M. And M. J. Hinich (1984): The spatial theory of voting: An introduction, CUP Archive.

Enos, R. D. And A. Fowler (2014): "Pivotality and Turnout: Evidence from a Field Experiment in the Aftermath of a Tied Election," Political Science Research and Methods, forthcoming.

Ezrow, L. (2008): "Parties' policy programmes and the dog that didn't bark: No evidence that proportional systems promote extreme party positioning," British Journal of Political Science, 38, 479-497.

Gallagher, M. (1991): "Proportionality, disproportionality and electoral systems," Electoral studies, 10, 33-51.

GEYs, B. (2006): "Explaining voter turnout: A review of aggregate-level research," Electoral Studies, 25, 637-663.

Grofman, B. And P. Selb (2009): "A fully general index of political competition," Electoral Studies, 28, 291-296.

- (2011): "Turnout and the (effective) number of parties at the national and district levels: A puzzle-solving approach," Party Politics, 17, 93-117.

Groseclose, T. (2001): "A model of candidate location when one candidate has a valence advantage," American Journal of Political Science, 45, 862-886.

Grosser, J. And T. R. Palfrey (2013): "Candidate Entry and Political Polarization: An Antimedian Voter Theorem," American Journal of Political Science.

Herrera, H., M. Morelli, And T. Palfrey (2013): "Turnout and power sharing," The Economic Journal. 
JACKMAN, R. W. (1987): "Political institutions and voter turnout in the industrial democracies," American Political Science Review, 405-423.

Jackman, R. W. AND R. A. Miller (1995): "Voter turnout in the industrial democracies during the 1980s," Comparative Political Studies, 27, 467-492.

LAAKSO, M. AND R. TAAGEPERA (1979): "Effective number of parties: A measure with application to West Europe," Comparative Political Studies, 12, 3-27.

Llavador, H. (2006): "Electoral platforms, implemented policies, and abstention," Social Choice and Welfare, 27, 55-81.

Matakos, K., O. Troumpounis, and D. Xefteris (2013): "Electoral Rule Disproportionality and Platform Polarization," in EPSA 2013 Annual General Conference Paper, Available at SSRN: http://ssrn.com/abstract=2225152, vol. 809.

OrTuÑo-Ortín, I. (1997): "A spatial model of political competition and proportional representation," Social Choice and Welfare, 14, 427-438.

Persson, T., G. Roland, G. Tabellini, et Al. (2007): "Electoral rules and government spending in parliamentary democracies," Quarterly Journal of Political Science, $2,155-188$.

Powell, G. B. (2000): Elections as instruments of democracy: Majoritarian and proportional visions, Yale University Press.

Powell JR, G. B. (1980): "Voting turnout in thirty democracies: Partisan, legal, and socio-economic influences," Electoral Participation: A Comparative Analysis, 534.

(1986): "American voter turnout in comparative perspective," American Political Science Review, 17-43.

Riker, W. H. And P. C. Ordeshook (1968): "A Theory of the Calculus of Voting," American Political Science Review, 25-42.

Riker, W. H., P. C. Ordeshook, And P. Hall (1973): An introduction to positive political theory, Prentice-Hall Englewood Cliffs, NJ.

Roemer, J. (1994): "A theory of policy differentiation in single issue electoral politics," Social Choice and Welfare, 11, 355-380.

SAPORITI, A. (2014): "Power sharing and electoral equilibrium," Economic Theory, 55, $705-729$.

Schofield, N. And M. Gallego (2011): Leadership or chaos: the heart and soul of politics, Springer.

Schofield, N. AND A.-S. Kurella (2013): "Party activists in the 2009 German federal elections," in this volume.

Schofield, N. And I. Sened (2006): Multiparty democracy: elections and legislative politics, Cambridge University Press. 
SElB, P. (2009): "A Deeper Look at the Proportionality-Turnout Nexus," Comparative Political Studies, 42, 527-548.

SERrA, G. (2010): "Polarization of what? A model of elections with endogenous valence," The Journal of Politics, 72, 426-437.

TAAGePeRA, R. (1986): "Reformulating the cube law for proportional representation elections," American Political Science Review, 80, 489-504.

Theil, H. (1969): "The desired political entropy," American Political Science Review, $63,521-525$.

Volkens, A., O. Lacewell, P. Lehmann, S. Regel, H. Schultze, AND A. WERnER (2012): The manifesto data collection, Manifesto Project (MRG/CMP/MARPOR), Berlin: Wissenschaftszentrum Berlin für Sozialforschung (WZB). 